\title{
Biodegradation efficacy of soil inherent novel sp. Bacillus tropicus (MK318648) onto low density polyethylene matrix
}

\author{
Sucharita Samanta ${ }^{1} \cdot$ Deepshikha Datta $^{2} \cdot$ Gopinath Halder ${ }^{1}[\mathbb{C}$
}

Received: 14 May 2020 / Accepted: 16 September 2020 / Published online: 3 October 2020

(c) The Polymer Society, Taipei 2020

\begin{abstract}
The biodegradation of low density polyethylene (LDPE) was studied by employing a microbial strain isolated from the dumping site soil. The bacterium strain was identified as Bacillus tropicus (Gen Bank Accession no: MK318648) by 16S rRNA sequencing. The growth of the strain was observed on virgin LDPE during the biodegradation process. The change in properties of LDPE films before and after bacterial strain incubation was observed by FTIR, SEM, AFM, contact angle, mechanical and optical testing. Loss in mechanical properties and changes in optical properties of the polymer matrix was observed. Weight reduction by $10.15 \%$ and fall in the value of tensile strength, elongation at break, tear strength, Young's Modulus, hardness and stiffness to $8.59 \mathrm{MPa}, 10.85 \mathrm{~mm}, 69.18 \mathrm{~N}, 272.36,37.6$ Shor D and 10,672.21 N/m respectively were observed after 40 days of incubation. The transparency and haze percentage were also changed to $93.7 \%$ and $18.6 \%$ respectively after the study period. The $\mathrm{pH}$ of the media was measured during incubation to evaluate the change due to formation of different extracellular and intracellular enzymes excreted by the strain. Hence, Bacillus tropicus could be an efficient microorganism to degrade 10-micron thickness LDPE films, thereby preventing its harmful impacts in the environment.
\end{abstract}

Keyword LDPE · Isolation · Bacillus tropicus $\cdot$ Microbial degradation $\cdot$ Weight reduction

\section{Introduction}

Over the last few decades, the uncontrolled use of synthetic polymers has tremendously provoked a vulnerable ecological threat and caused worldwide anxiety. Synthetic polymers have entered in our day to day life and everywhere quickly due to its availability, durability, resistivity, and low cost. Each year around 140 million tons of synthetic polymers are accumulated around the planet [1]. Almost 8,000,000 tons of plastic products are consumed in India alone every year according to an immediate evaluation of the Central Pollution Control Board, New Delhi, India [2]. People often dispose of the widely used polymer materials unconsciously, which generate pollution in the air, water bodies as well as in soil. The estimation from a computed ratio implies that

Gopinath Halder

gopinathhaldar@gmail.com

1 Department of Chemical Engineering, National Institute of Technology Durgapur, Mahatma Gandhi Road, Durgapur, West Bengal 713209, India

2 Department of Chemical Engineering, GMR Institute of Technology, Rajam, Andhra Pradesh 532127, India
LDPE degradation is very slow and it takes almost 300 years to decay completely under the natural condition of the ecosystem [3]. The packaging industry suffers a huge demand for thin plastics (less than 30-micron) for various applications like disposable shopping bags, one-time-use packaging materials, etc. [4]. But unfortunately, the thin plastic bags are spread in the atmosphere easily due to its lightweight and parachuted shaped design. Even after long exposure to sunlight and atmospheric agents, they become fragile and readily fragmented into small, persistent fragments, commonly called microplastics, which has a huge environmental impact and high health risk because of their selective adsorption potential for xenobiotics and other chemical substances, in particular those with low water solubility [5, 6]. Actually, for the case of single-use plastic packaging materials, the lightweight plastic bags less than 50-micron thickness and ultra-thin plastic bags of thickness less than 15 micron, the percentages of recovery rate are even lower and hence a bulk of these items are incinerated in landfills [7]. Prohibition was also used in attempts to curb the use of disposable plastics by imposing certain strict rules in it like: in 2008 China has banned the distribution, production, and use of plastics less than 25-micron thickness. Similarly, in 2003, South Africa 
has banned disposable plastics less than 30-micron thickness [8]. But the excessive demand and huge beneficial effect of the film have resulted in its massive application leading to its accelerated accumulation in the environment. This has led the researchers to pay attention to introduce environmentally sound contrivance by which the synthetic polymeric materials can be easily degraded. Several methods have been reported for the mechanical recycling of plastic wastes by per-oxidation succeeded by bio-assimilation of the oxidized products [9] and few approaches have also been accepted for the post-consumer recycling for the disposal of polymeric materials for the betterment of the environment [10]. Scientists have also focused on different techniques of degradation of synthetic polymers such as UV-irradiation, chemical [11], thermal and thermochemical, photo-oxidative degradation [12] to convert the long-chain polymers into its simple structured monomers or oligomers which can diminish the ecological threat somehow.

To establish an energy-efficient, low cost, and technically effective method of plastic degradation, the researchers around the sphere have emphasized the biological degradation of synthetic polymers in which the microorganisms assuredly fragment the convolutedly structured polymers. Microbial degradation of the synthetic polymer is considered to be superior over the other techniques due to the elementary existence of different microbial strains in our territory. Eleven fungal along with 17 bacterial genera have been already reported to be associated with the degradation of polyethylene [13]. Formerly microbial degradation of LDPE has been revealed by various researchers to be occurring to various extents using Pseudomonas sp. AKS2 [14], Aspergillus clavatus strain JASK1 [15], Rhizopus oryzae NS 5 [16], Bacillus circulans, Bacillus brevies, and Bacillus sphaericus [17], Penicillium pinophilum and Aspergillus niger [18], Bacillus pumilus, Bacillus halodenitrificans, Bacillus cereus [19], Bacillus subtilis [20] and many more.

In the field of polymer degradation study, the thickness is a vital parameter affecting its applicability and adaptability in various sectors like agricultural, packaging, industrial and many more diversified application areas. Conforming to the Environmental Management Act, the thick plastics are comparatively more reliable over correlatively thin plastics and hence can reduce the solid waste generation in the ecosystem [21]. Therefore, the degradation of relatively thick plastic material demands more attention. Due to the rapid use of plastics of different thickness and unconscious disposal of them, after the long exposure to sunlight and atmospheric agents, the thin plastics become more fragile and readily fragmented into small, persistent fragments, and produce microplastics easily rather than thick plastics. The microplastic has a huge environmental impact and high health risk because of their selective adsorption ability for xenobiotics and other chemical substances, in particular those with low water solubility [6]. In the process of in-vitro degradation using microorganisms, the polymeric skeleton goes through de-polymerization to produce organic matter such as water, carbon-di-oxide and biomass. But the maximum weathered plastics are fragmented into microplastics (MPs) which has a major impact on the environment [22]. Microplastics mainly have negative impact on the aquatic life of marine as well as freshwater environment [23]. The physical effects of ingesting MPs are blockage of the alimentary appendages and of the digestive system, inflammation and laceration of the gastrointestinal tissues which will inhibit the accurate absorption of nutrients [24]. According to recent report, MPs in the soil can act as distinct microbial communities colonized by specific assemblages, including potential plasticdegrading bacteria [25]. Microbial degradation has greatly affected the transformation of MPs by offering the support of microbial colonization and growth along with serving as carbon sources [26]. So, only in the microbial degradation process, it can be assuredly proclaimed that the macro and micro-sized plastics can be well degraded and can cure the environment from the alarming threat of plastic pollution. Though many microbes associated with polyethylene deterioration have been reported, however further advancement to reinforce the degradation percentage of these materials is eminently requisite. The degradation study of comparatively thin plastics (less than 20-micron thickness) has not been done yet. Various numbers of microbial strains have been reported to impose the effectiveness to degrade LDPE films as shown in Table 1.

The purpose of the current investigation is to evaluate the biodegradation efficacy of the microbial strain isolated from the dumping site soil onto the environmental pollution creating low-density polyethylene matrix of 10-micron thickness. The study focuses on the mechanism of degradation of LDPE film in natural disposal environment giving a more realistic degradation prospect of the polyolefin film. The authenticity of the degradation mechanism prospect is detailed by scaling up the process in the laboratory by undergoing the degradation mechanism using cultured microorganism isolated from the disposal environment. The results indicated a huge prospect of the microbial species to enhance the degradation of the synthetic film in normal environmental conditions. Further, the work also elaborates on the significance of the capability of very thin films to undergo degradation by microbes suggesting a way through which unavoidable packaging films can be handled. The morphological deviations of LDPE film were studied after degradation through FTIR, SEM, AFM and compared with its initial stage. After incubation of virgin LDPE film into inoculated microbial strain, the reduction in weight percentage and change in $\mathrm{pH}$, mechanical properties (tensile strength, elongation at break, tear strength, Young's modulus, hardness and stiffness) and optical properties (haze, 
Table 1 Different microbial strains capable of degrading polymers.

\begin{tabular}{|c|c|c|c|c|c|}
\hline Sl no. & Organisms involved in Degradation & $\begin{array}{l}\text { Used Materials } \\
\text { (Thickness) }\end{array}$ & $\begin{array}{l}\text { Duration of Incu- } \\
\text { bation }\end{array}$ & $\begin{array}{l}\text { Weight loss } \\
(\%)\end{array}$ & References \\
\hline 1. & Bacillus amyloliquefaciens(BSM-1) & LDPE $(20 \mu \mathrm{m})$ & 60 days & 11 & [34] \\
\hline 2. & Bacillus amyloliquefaciens (BSM-2) & LDPE $(20 \mu \mathrm{m})$ & 60 days & 16 & {$[34]$} \\
\hline 3. & Aspergillus clavatus JASK1 & LDPE $(20 \mu \mathrm{m})$ & 90 days & 35 & {$[15]$} \\
\hline 4. & Aspergillus japonicas & LDPE $(20 \mu \mathrm{m})$ & 30 days & 11.11 & {$[44]$} \\
\hline 5. & Aspergillus niger & LDPE $(20 \mu \mathrm{m})$ & 30 days & 5.8 & [44] \\
\hline 6. & Rhodococcus ruber & LDPE $(0.2 \mathrm{~mm})$ & 60 days & 7.5 & [45] \\
\hline 7. & Pseudomonas putida & LDPE $(20 \mu \mathrm{m})$ & 120 days & 9 & {$[30]$} \\
\hline 8. & Pseudomonas syringae & LDPE $(20 \mu \mathrm{m})$ & 40 days & 11.3 & {$[30]$} \\
\hline 9. & Aspergillus nomius & LDPE $(20 \mu \mathrm{m})$ & 90 days & 4.9 & [46] \\
\hline 10. & Streptomyces sp. strain AJ1 & LDPE $(20 \mu \mathrm{m})$ & 90 days & 5.2 & [46] \\
\hline 11. & Pseudomonas aeruginosa strain SKN1 & LDPE $(20 \mu \mathrm{m})$ & 60 days & 10.32 & {$[32]$} \\
\hline 12. & Brevibacillus borstelensis & LDPE $(20 \mu \mathrm{m})$ & 30 days & $6.2 \pm 0.3$ & {$[35]$} \\
\hline 13. & Kocuria palustrisM16 & LDPE $(20 \mu \mathrm{m})$ & 30 days & $1 \pm 0.033$ & {$[32]$} \\
\hline 14. & Bacillus pumilusM27 & LDPE $(20 \mu \mathrm{m})$ & 30 days & $1.5 \pm 0.038$ & {$[32]$} \\
\hline 15. & Bacillus subtilis $\mathrm{H} 1584$ & LDPE $(20 \mu \mathrm{m})$ & 30 days & $1.75 \pm .06$ & {$[32]$} \\
\hline 16. & Bacillus tropicus & 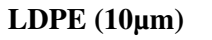 & 40 days & 10.15 & Present study \\
\hline
\end{tabular}

Table 2 Properties of LDPE film used in the present study.

\begin{tabular}{ll}
\hline Property & LDPE Film \\
\hline Thickness (microns) & 10 \\
Density $\left(\mathrm{kg} / \mathrm{m}^{3}\right)$ & 975 \\
Melting point $\left({ }^{\circ} \mathrm{C}\right)$ & 121 \\
Water Absorption Percentage $(\%)$ & 0.01 \\
\hline
\end{tabular}

transmittance) were also evaluated. The work emphasizes the ability of the available microbial strain in the dumping site to degrade the synthesized LDPE film, so as to put up the actual view of the degradation process occurring in the natural environment.

\section{Materials and method}

\section{Materials}

In the current study, low-density polyethylene of 10-micron thickness was purchased from Relene Petrochemicals Limited, Mumbai. The different properties of the used LDPE film had been stated in Table 2. The LDPE strips of $9 \mathrm{~cm} \times 3.5 \mathrm{~cm}$ were washed with de-ionized water and then they were dipped into $70 \%(\mathrm{v} / \mathrm{v})$ solution of ethanol for $30 \mathrm{~min}$ to sterilize it. After sterilization, it was dried for $2 \mathrm{~h}$ at $60{ }^{\circ} \mathrm{C}$ and then air-dried in a laminar airflow chamber for $15 \mathrm{~min}$. Ethanol, used in this experiment, is of analytical reagent grade, and other required chemicals were obtained from HIMEDIA Laboratories, Mumbai, India, and Sisco
Research Laboratories Pvt. Ltd., Mumbai, India. For microbial isolation and culture purpose, $2 \%$ agar powder from HIMEDIA Laboratories and $1.3 \%$ LB media (Lennox) containing $10 \mathrm{~g} / \mathrm{L}$ Tryptone, $5 \mathrm{~g} / \mathrm{L} \mathrm{NaCl}, 5 \mathrm{~g} / \mathrm{L}$ Yeast extract from Sisco Research Laboratories Pvt. Ltd., Mumbai were utilized. M9, minimal salts, $5 \mathrm{X}$ medium containing $33.9 \mathrm{~g} / \mathrm{L}$ $\mathrm{Na}_{2} \mathrm{HPO}_{4}, 15 \mathrm{~g} / \mathrm{L} \mathrm{KH}_{2} \mathrm{PO}_{4}, 5 \mathrm{~g} / \mathrm{L} \mathrm{NH}_{4} \mathrm{Cl}$ and $2.5 \mathrm{~g} / \mathrm{L} \mathrm{NaCl}$ from Sigma-Aldrich was used for screening and further invitro degradation study purpose.

\section{Microbial strain isolation from soil and preparation of culture media}

The soil sample was collected in a zip-lock packet from the dumping site of City center, Durgapur, India as shown in Fig. 1. The soil $\mathrm{pH}$ and moisture content were found to be 7.87 and $16.96 \%$ respectively initially at the time of soil sample collection. The soil sample of $1 \mathrm{~g}$ was then diluted with $10 \mathrm{ml}$ de-ionized water, and the supernatant was used as a stock solution. Serial dilution was done taking the stock solution from $10^{-1}$ to $10^{-6}$ concentration for microbial isolation.

All the glassware used in the following experiment were washed with $10 \% \mathrm{HCl}$ and dried. To formulate the microbial culture media for isolation purpose, de-ionized water with $2 \%$ agar powder from HIMEDIA and 1.3\% LB (Lennox Broth) media containing $10 \mathrm{~g} / \mathrm{L}$ Tryptone, $5 \mathrm{~g} / \mathrm{L} \mathrm{NaCl}$, $5 \mathrm{~g} / \mathrm{L}$ yeast extract from Sisco Research Laboratories Private Limited, Mumbai were autoclaved to sterile at $121{ }^{\circ} \mathrm{C}$ temperature and 15 psi pressure for $15 \mathrm{~min}$. After that $100 \mu \mathrm{L}$ serially diluted supernatant soil sample was taken to spread 
Fig.1 Isolated bacterial strain sampling site (City Center, Durgapur, India)

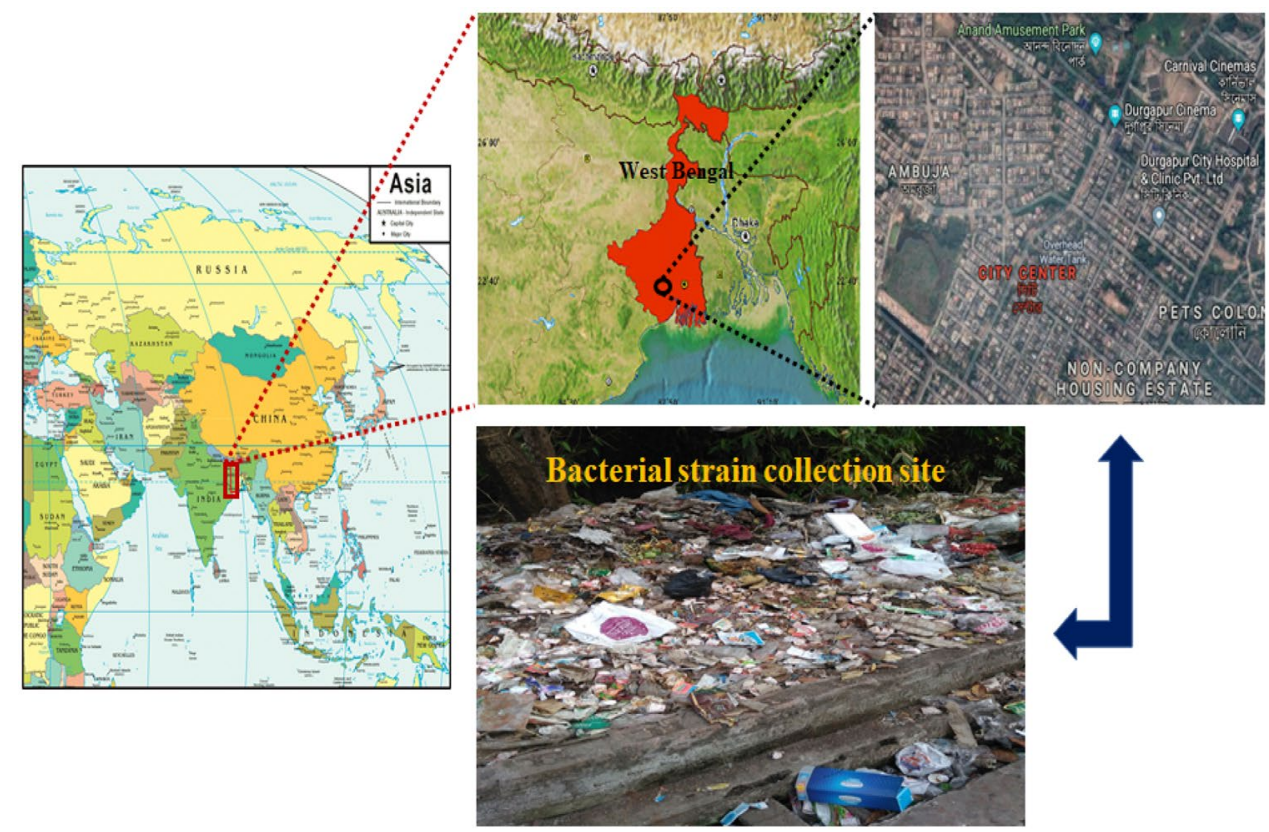

over the LB media containing agar plate through the 'spread plate technique' and was kept in BOD incubator at $37{ }^{\circ} \mathrm{C}$ for $24 \mathrm{~h}$. Petri-dish containing LB media along with agar, revealing distinct microbial colonies were stipulated and these were streaked over another series of LB media and agar accommodating petri-dishes for further experimental purpose. Initially, five isolates were found and all of them were screened for LDPE degradation in the batch method in the presence of 5X minimal salt medium. Among all these isolates, the reporting microbe was found to be the best capable of degrading the virgin LDPE.

Different biochemical characterizations and gram reactions were analyzed and reported in Tables 3 and 4 respectively. Figure 2 describes the isolation procedure of the particular strain involved in the present study. The isolated bacterium was identified through $16 \mathrm{~S}$ rRNA sequencing.

For the assessment of the degradation capability of LDPE films in presence of the isolated bacterium, the culture medium was prepared with M9, minimal salts after autoclaving it at $121{ }^{\circ} \mathrm{C}$ temperature and 15 psi pressure for $15 \mathrm{~min}$. The isolated novel bacterium strain was inoculated in the liquid medium with the sterilized LDPE film.

\section{$16 \mathrm{~S}$ rRNA sequencing of the isolated strain}

Proper identification of any microbial strain is performed most preferably by the $16 \mathrm{~S}$ rRNA technique in the case of taxonomic and phylogenetic study. For the bio-informatic study of identification and detection of the bacterial strain, this technique is highly recommended above all as the $16 \mathrm{~S}$ rRNA gene consists of $1500 \mathrm{bp}$ (basic pair), which is truly large to be used [27]. The bacterium genomic DNA was
Table 3 Bio-chemical characterizations of the isolate.

\begin{tabular}{|c|c|c|}
\hline Serial No. & Characteristics & Results \\
\hline 1. & Catalase & “+” ve \\
\hline 2. & Oxidase & “+” ve \\
\hline 3. & Arginine di-hydrolase & “+” ve \\
\hline 4. & Citrate utilization & “+” ve \\
\hline 5. & Acetoin production & “+” ve \\
\hline 6. & Gelatinase & “+” ve \\
\hline 7. & $\beta$-galactosidase & "-" ve \\
\hline 8. & Lysine decarboxylase & "-" ve \\
\hline 9. & Ornithine decarboxylase & "-" ve \\
\hline 10. & $\mathrm{H}_{2} \mathrm{~S}$ production & "-" ve \\
\hline 11. & Urease & “-” ve \\
\hline 12. & Tryptophan desaminase & “-" ve \\
\hline 13. & Indole production & "-" ve \\
\hline 14. & Glucose fermentation & "-" ve \\
\hline 15. & Mannitol fermentation & "-" ve \\
\hline 16. & Inositol fermentation & “-" ve \\
\hline 17. & Sorbitol fermentation & “-” ve \\
\hline 18. & Arabinose fermentation & “-" ve \\
\hline 19. & Glycogen fermentation & "+" ve \\
\hline 20. & D-ribose fermentation & “+” ve \\
\hline 21. & D-glucose fermentation & "-" ve \\
\hline 22. & Maltose fermentation & "+" ve \\
\hline 23. & Potassium gluconate & “+” ve \\
\hline
\end{tabular}

specifically isolated by using the BDT v3.1 Cycle sequencing kit on ABI 3730xl Genetic Analyzer (Thermo Fisher Scientific, USA). The fragment of the 16S rDNA gene was partially amplified by performing a single discrete polymerase 
Table 4 Culture characteristics of the isolate.

\begin{tabular}{lll}
\hline Serial No. & Characteristics & Results \\
\hline 1. & Gram reaction & Gram “+” ve \\
2. & Morphology & Rods \\
3. & Colour & Off-white \\
4. & Endospore formation & “+”ve \\
5. & Elevation & Central elliptical \\
6. & Motility & Motile \\
\hline
\end{tabular}

chain reaction (PCR) using the bacteria definitive universal primers 27F (5'- AGAGTTTGATCMTGGCTCAG) and 1492R (5'- TACGGYTACCTTGTTACGACTT). Using aligner software accord sequence of the 16SrDNA gene was developed from the forward and the reverse sequence data. The polymerase chain reaction (PCR) amplicon was purified from Agarose gel to discard the contaminants. The 16S rRNA gene sequence was used to accomplish BLAST with the Gen Bank NCBI (National Centre of Biotechnology Information), Bethesda MD, USA, database and maximum similarity sequence was compared. The first ten sequences were selected to build upon the maximum identity score and also aligned by multiple alignment software program Clustal W. For distance matrix generation, bootstrap analysis along with the un-rooted phylogenetic tree construction, MEGA 7 software was utilized together with the implantation of the BioNJ algorithm.

\section{Growth kinetics of Bacillus tropicus (MK318648)}

The growth kinetics study of Bacillus tropicus was performed for assessing whether the particular strain of bacteria which has been isolated from the waste side is capable of getting adapted in the new environment to metabolize the certain substrate in which it is inoculated. The bacterial growth occurs in the process of binary fission through which genetically identical cells to the original cells are produced without any mutational event.
The growth kinetics of the isolated bacterial strain Bacillus tropicus (MK318648) was determined by determining the optical density (OD) at $540 \mathrm{~nm}$ using UV-Spectrophotometer (Shimadzu spectrophotometer, UV-1800, Japan). According to the methodology reported by Zakaria [28], dry cell weight (DCW) in $\mathrm{g} / \mathrm{L}$ was determined gravimetrically after drying the bacterial cells at $70{ }^{\circ} \mathrm{C}$. The relationship between DCW and OD was established by linear regression. Figure 3 shows the pattern of bacterium growth. Biomass productivity or specific growth rate, $\mathrm{P}$ in $\mathrm{g} \mathrm{L}^{-1} / \mathrm{h}$ was estimated from the difference in biomass concentration $\left(\mathrm{g} \mathrm{L}^{-1}\right)$ within a cultivation time in hours $(\mathrm{h})$ according to the following Eq. (1) [29]:

$P=\frac{a_{1}-a_{0}}{t_{1}-t_{0}}$

where, $a_{1}$ and $a_{0}$ were the final and initial biomass concentration $\left(\mathrm{g} \mathrm{L}^{-1}\right)$ at the times $t_{1}$ and $t_{0}$ hours respectively. Specific growth rate $\mu\left(\mathrm{h}^{-1}\right)$ was determined from the following Eq. (2):

$\mu=\frac{\ln \left(a_{1}-a_{0}\right)}{\left(t_{1}-t_{0}\right)}$

\section{In-vitro degradation study}

After isolation of the microbial strain, it was inoculated in Erlenmeyer flasks with $100 \mathrm{ml}$ sterilized liquid media containing 1.3\% minimal salt media in de-ionized water and identically weighed disinfected LDPE strips were put into it. Then it was kept in BOD incubator at $37^{\circ} \mathrm{C}$ for $10,20,30$ and 40 days respectively at $120 \mathrm{rpm}$. Another Erlenmeyer flask containing $100 \mathrm{ml}$ sterilized liquid media was inoculated with microbial strain and kept in an incubator without immersing LDPE under the same condition for comparative study only.
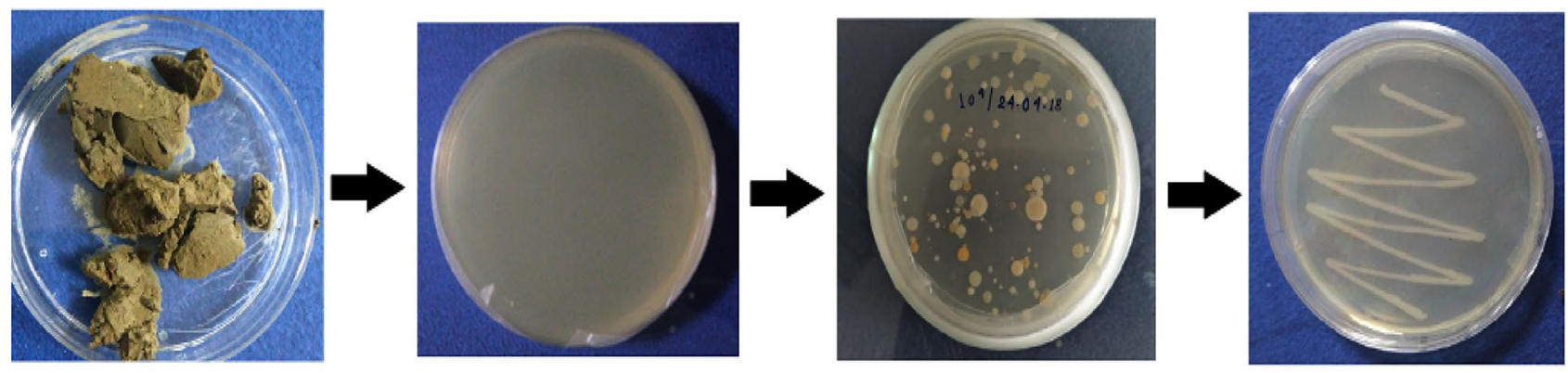

Fig. 2 Schematic diagram representing the isolation of microbial colony in LB media containing agar plate from dumping site soil 
Fig. 3 Schematic representation of the experimental investigation

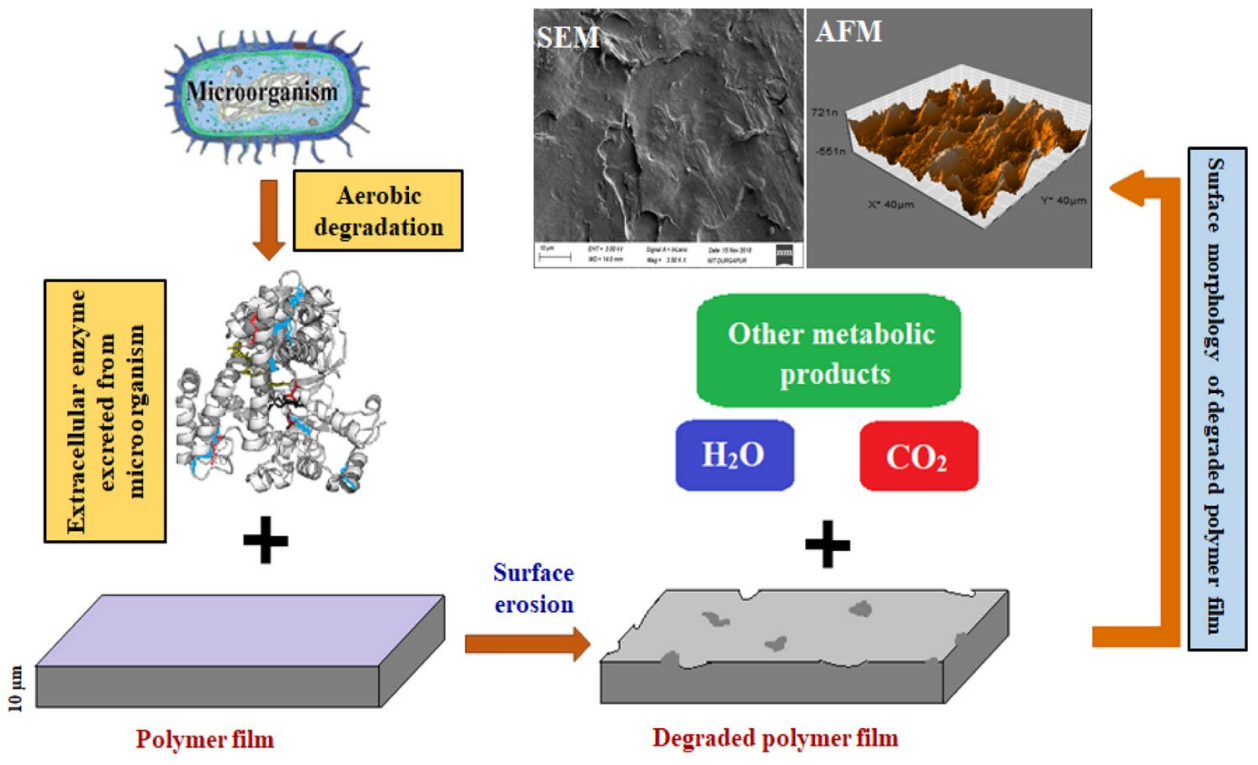

\section{LDPE film harvesting}

After 10, 20, 30 and 40 days of incubation, the LDPE films were unfastened from the microbial medium to separate the microbial biomass from the experimental LDPE films. Then the films were washed with de-ionized water for more than 3 times and then they were immersed in 2\% (v/v) SDS solution for $1 \mathrm{~h}$ to free them from the metabolic protein of the culture media. After that, the LDPE strips were dried at $60{ }^{\circ} \mathrm{C}$ for a few hours to use them for different characterization and analysis.

\section{Characterization}

\section{Weight reduction}

Weight reduction of plastic material is highly desirable in the study of polymeric degradation to reduce the solid waste generation in our ecosystem. In this regard, the weight reduction percentage of the LDPE films immersed in the microbial media was measured. The weight of the films after 10, 20, 30 and 40 respective days of incubation was measured against the initial weight before incubation. The percentage of weight reduction was calculated by Eq. (3) [30]:

Weight reduction percentage $=\frac{W_{i}-W_{f}}{W_{i}} \times 100$

Where, $W_{i}$ and $W_{f}$ are the weight of the LDPE films before and after incubation, respectively.

\section{Influence of pH}

In the case of microbial degradation, $\mathrm{pH}$ is a crucial parameter to detect the proper reason behind the polymeric degradation rate. Change in $\mathrm{pH}$ generally gives the evidence of metabolic activities of microbial strain in the growth medium. The $\mathrm{pH}$ of growth media was estimated at a different interval of days by Eutech Instrument $\mathrm{pH}$ Tutor before and after incubation of the films.

\section{Contact angle}

The contact angle is the angle made between the solid surface to be tested and the drop of liquid falling on it to measure the hygroscopic nature and the uniformity of the sample surface under testing. Actually, it emphasizes on the hygroscopic nature of the surface of any solid material. At a particular pressure and temperature, any system consisting of solid, liquid, and vapor, acquire a unique equilibrium contact angle. Conventionally, when the contact angle of water is less than $90^{\circ}$, the solid surface is anticipated to be hydrophilic and when the water contact angle is greater than $90^{\circ}$, the solid surface is considered as hydrophobic while testing with any solid material as well as the presently investigated LDPE strips before and after incubation.

The analysis was executed by using the Kruss Drop shape Analyzer, model no: DSA25 (Singapore). In the current study, the liquid used for contact angle measurement 
is of Millipore grade de-ionized water. The contact angle was measured at room temperature. The average of three consecutive assessments has been reported.

\section{Fourier-transform infrared spectroscopy (FTIR)}

Fourier-transform infrared spectroscopy (FTIR) provides different superficial chemical changes in the materials. The study of FTIR can interpret the existence of various functional groups present in the LDPE films as well as the chemical modification prevailed during incubation and its initial state. Morphological changes in long-chain polymeric structure were analyzed in FTIR Spectrophotometer, Model no: FT-IR C109292 (Perkin Elmer, UK) in software version 10.5.4. The FTIR spectra were noted at $4.0 \mathrm{~cm}^{-1}$ resolution from the frequency range of $4000 \mathrm{~cm}^{-1}$ to $400 \mathrm{~cm}^{-1}$ by the accumulation of 4 scans at room temperature.

\section{Scanning electron microscopy (SEM)}

The surface morphological study of LDPE films, before and after incubation with microbial strain, was performed by SEM analysis using a scanning electron microscope, which is a type of electron microscope that generates images of the given sample through scanning the surface with the help of enrapt beam of electrons. For SEM analysis, the LDPE strips of the initial state and after the incubation period of 40 days were cut into small pieces and were coated with gold powder. Afterward, different images were taken by Scanning electron microscope ZEISS (Germany) by $0.5 \mathrm{KX}$ to $3.5 \mathrm{KX}$ magnification and $3.00 \mathrm{kV}$ acceleration voltage at room temperature.

\section{Atomic force microscopy (AFM)}

Atomic force microscopy is an extremely elevated resolution type of a scanning inquest microscopy which is used to configure an image of the three-dimensional physique of the given sample surface at an intense resolution. The polymeric films before and after incubations were taken out from the experimental medium using proper technique to place the small pieces of the films on a cleaned glass-slide and images were taken at the scan speed of $1.0 \mathrm{~Hz}$ in dynamic force operation mode within $500 \mathrm{mV}$ to $1 \mathrm{~V}$ free vibration amplitude by Nanoscurf C3000 (Switzerland), Software version 3.5.0.29 in air through using FLEXAFM type of head.

\section{Mechanical and optical property analysis}

The mechanical properties of polymeric films play a significant role as it justifies the applicability of the film for different purposes. Different mechanical properties such as tensile strength, elongation at break, Young's Modulus, and stiffness were examined in the Universal Tensile Testing Machine (3382, Instron, UK) according to ASTMD 882-91 Standard method. The hardness was measured using Durometer - Shore Hardness Tester (Qualitest, Canada) according to ASTMD 2240 standard method. The tear strength test was conducted using Digital Tear Resistance Tester (ATS-100, Italy) according to ASTMD 1922.

The degradation of the incubated films can also be justified by conducting the loss in optical properties in terms of an increase in haze and a decrease in transmittance of the films. Haze and transmittance of the LDPE films were measured at its initial state and compared with the changes observed after 10,20, 30 and 40 days interval of incubation in microbial strain. To determine the change in Haze and Transparency, the Hazemeter (RDM Test Equipment, Model-EEL, England) was used as reported by ASTM D1003 Standard method.

\section{Results and discussion}

The isolated microbe has been used to study the decomposition of LDPE due to its capability to form highly worthwhile extracellular enzymes, which assist in the attack on the surface of the polymer and thereby instigating the rate of degradation of LDPE through surface erosion technique without harming the ecosystem. After 40 days of incubation, the degraded LDPE film was characterized with the control LDPE film during the different intervals of time, and noteworthy changes which promisingly assured the degradation of the film was reported. The experimental findings have been elaborately discussed below and summarily exemplified in Fig. 3.

\section{5 rRNA sequencing of Bacillus sp.}

The identification based on polymerase chain reaction (PCR) amplicon was observed in a 1500 bp 16S rRNA fragment, which was thereafter sequenced. The obtained result on the groundwork 16S rRNA gene sequencing, showed a 97\% similarity of the isolated strain with Bacillus tropicus as shown in Fig. 4. The sequence data were submitted to National Centre for Biotechnology Information (NCBI), Bethesda $\mathrm{MD}$, USA, to obtain the unique accession number for the identified isolate. The accession number updated by NCBI is Bacillus tropicus sp. MK318648.

\section{Biomass productivity and specific growth rate of Bacillus tropicus}

The biomass productivity $(\mathrm{P})$ and specific growth rate $(\mu)$ of Bacillus tropicus while the LDPE film was immersed in the liquid media were calculated using Eq. (1) and Eq. (2), 
Fig. 4 Phylogenetic assay of Bacillus tropicus based on 16S rRNA gene nucleotide sequences. Bootstrap values indicated by the numbers at the nodes are obtained from the neighbor-joining analysis of 1000 re-sampled database

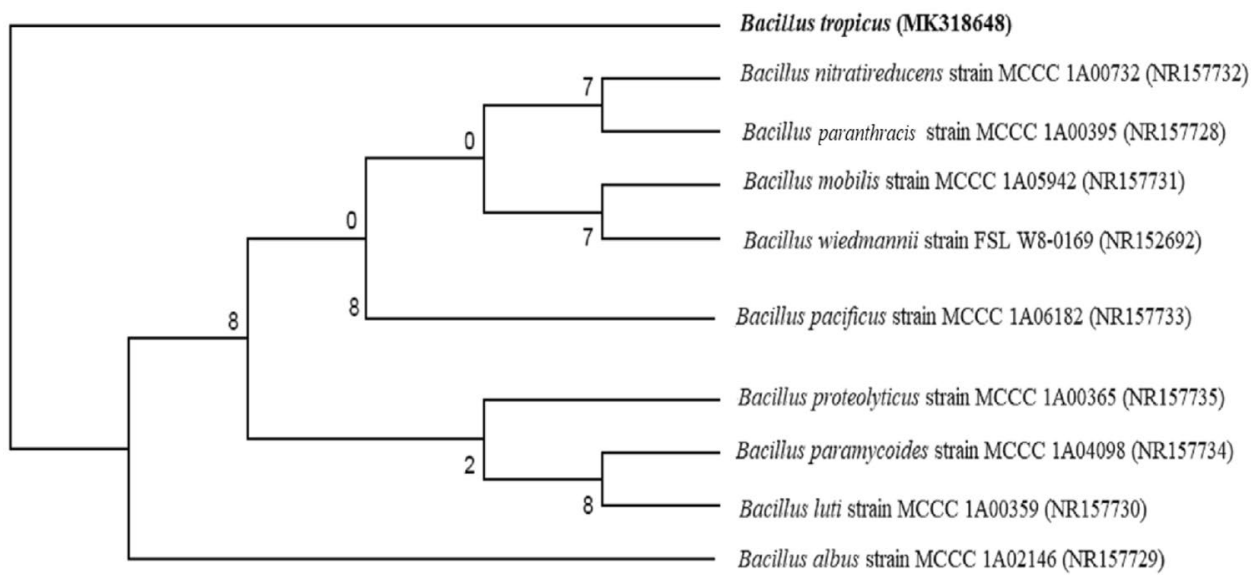

Fig. 5 Growth curve of Bacillus tropicus (MK318648)

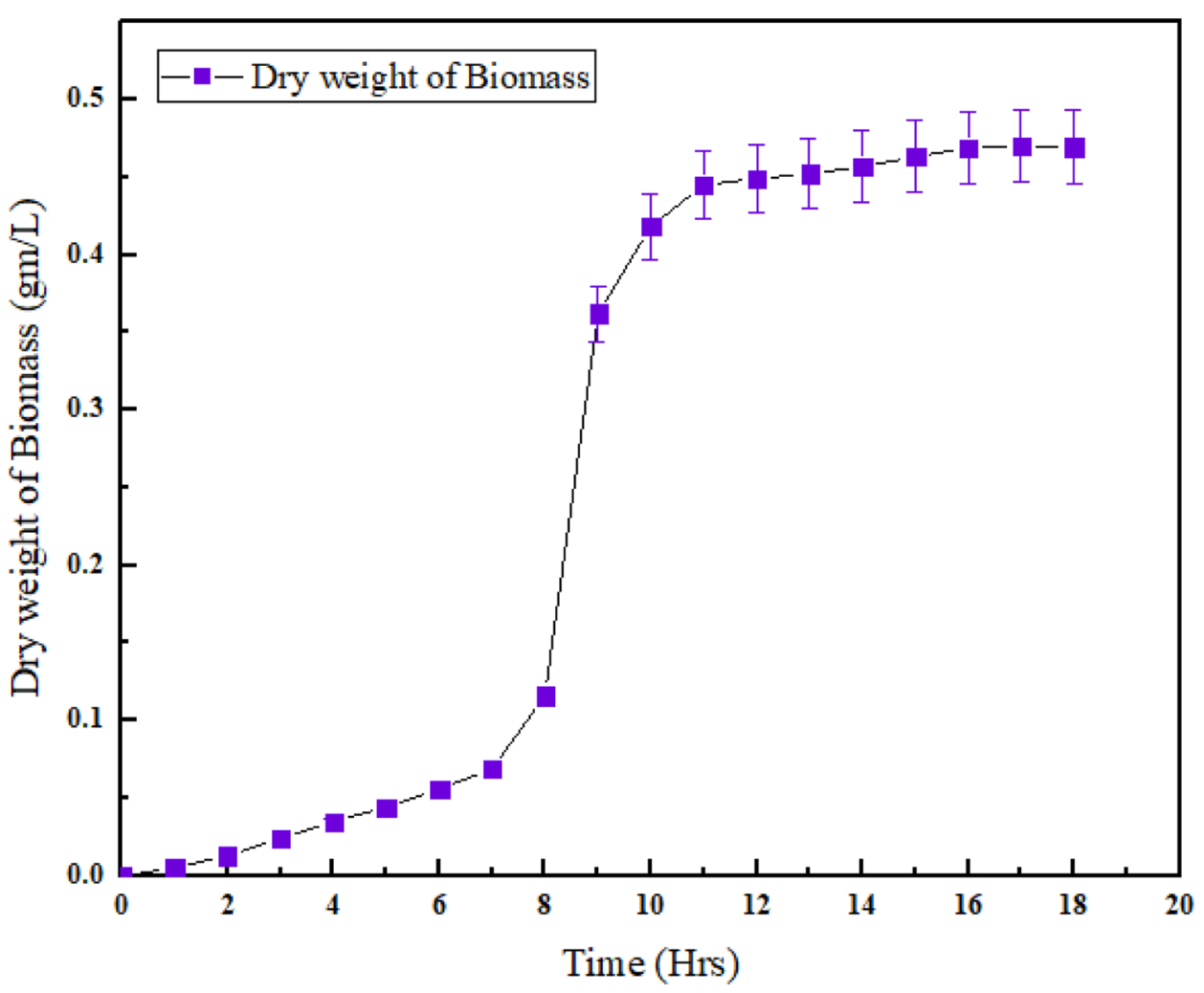

respectively. The biomass productivity and the specific growth rate of the bacterium were estimated to be $0.246 \mathrm{~g}$ $\mathrm{L}^{-1} \mathrm{~h}^{-1}$ and $1.138 \mathrm{~h}^{-1}$ respectively from the data of Fig. 5 considering the higher and lower value of the exponential phase in the growth curve. Actually, during the lag phase of the bacterial growth cycle, synthesis of different enzymes, RNA, and other molecules occurs. Throughout the lag phase, the bacterial cells change very slightly as they are unable to reproduce in a new medium immediately.

The log phase, also known as the exponential phase is the period which can be characterized by cell doubling [31]. In this phase, a sharp change in bacterial biomass with corresponding time has been shown in the growth curve in Fig. 5.

\section{Weight reduction}

The efficient and elementary approach to quantify the rate of biodegradation of any polymer film is by deducing the weight loss percentage. Polymer materials are made of longchain carbon atoms, which are utilized by the microbes to produce the metabolized enzyme. Biodegradation of polymeric materials in the environment starts with 'bio-deterioration' process. Long chain polymers, when acted upon by 
the enzymes, are reduced into small chains or monomers followed by aerobic or anaerobic degradation for complete mineralization. It had shown that enzyme attack the amorphous regions initially and then the crystalline regions. In this step, the polymeric materials are first fragmented into small fractions by the action of microbial communities with the help of several other decomposing organisms and abiotic agents present in the particular surroundings. Subsequently the polymeric backbones are cleaved by different hydrolytic enzymes (as well as other catalytic agents such as free radicals) produced by the biodegrading microorganisms. This results in the progressive reduction of the molecular weight of the polymer [32]. Some of the degradation products can be assimilated by the micro-organisms leading to mineralization of organic compounds and generation of new biomass. Hence, it is evident that enzymatic degradation plays the most important role in the biodegradation of polymers.

The weight loss percentage builds upon the surface area of the polymer as microbial degradation is triggered at the accessible surface of the films by utilizing the sole carbon atoms. In this present study, the novel sp. Bacillus tropicus (MK318648) has proven its important role in the degradation of the polymer film very effectively. To evaluate the loss of weight percentage at different intervals of time the weight of the sterilized LDPE film before incubation was compared with the incubated (with Bacillus tropicus at $37^{\circ} \mathrm{C}$ ) films.
For biodegradation of LDPE different microorganisms like Pseudomonas sp. AKS2, [14], Rhodococcus rubber [33], Bacillus amyloliquefaciens [34], Brevibacillu sborstelensis [35] and many more were used to degrade the polymer materials. However, the bio-degradation of the LDPE film with Bacillus tropicus species has not been studied yet. It was found very emphatically that the bacterium sp. effectively confirmed the capability of degrading the LDPE film by the process of intake of carbon atoms from the LDPE film surface. In the present investigation, a loss of $10.15 \%$ ( Fig. 6) in the weight of Bacillus tropicus treated LDPE film was observed after 40 days of incubation.

\section{Change in pH}

Change in $\mathrm{pH}$ endorsed that the culture media is stationarily active to be metabolized through which growth of the microbes can proceed. The present study reports the change in $\mathrm{pH}$ of the culture media along with the control media depending on time. The $\mathrm{pH}$ of the LB media at its initial state was 6.31 , which increased successively up to 8.84 when the microbial strain was added. Whereas in the control media in which the microbial strain was not added, $\mathrm{pH}$ was not increased at all compared to the microbial culture media. In Fig. 7, the comparative changes in $\mathrm{pH}$ between the microbial culture media and the controlled media have been
Fig. 6 Variation in weight loss percentage of LDPE when it was treated with the novel bacterial strain at $37^{\circ} \mathrm{C}$ for 40 days

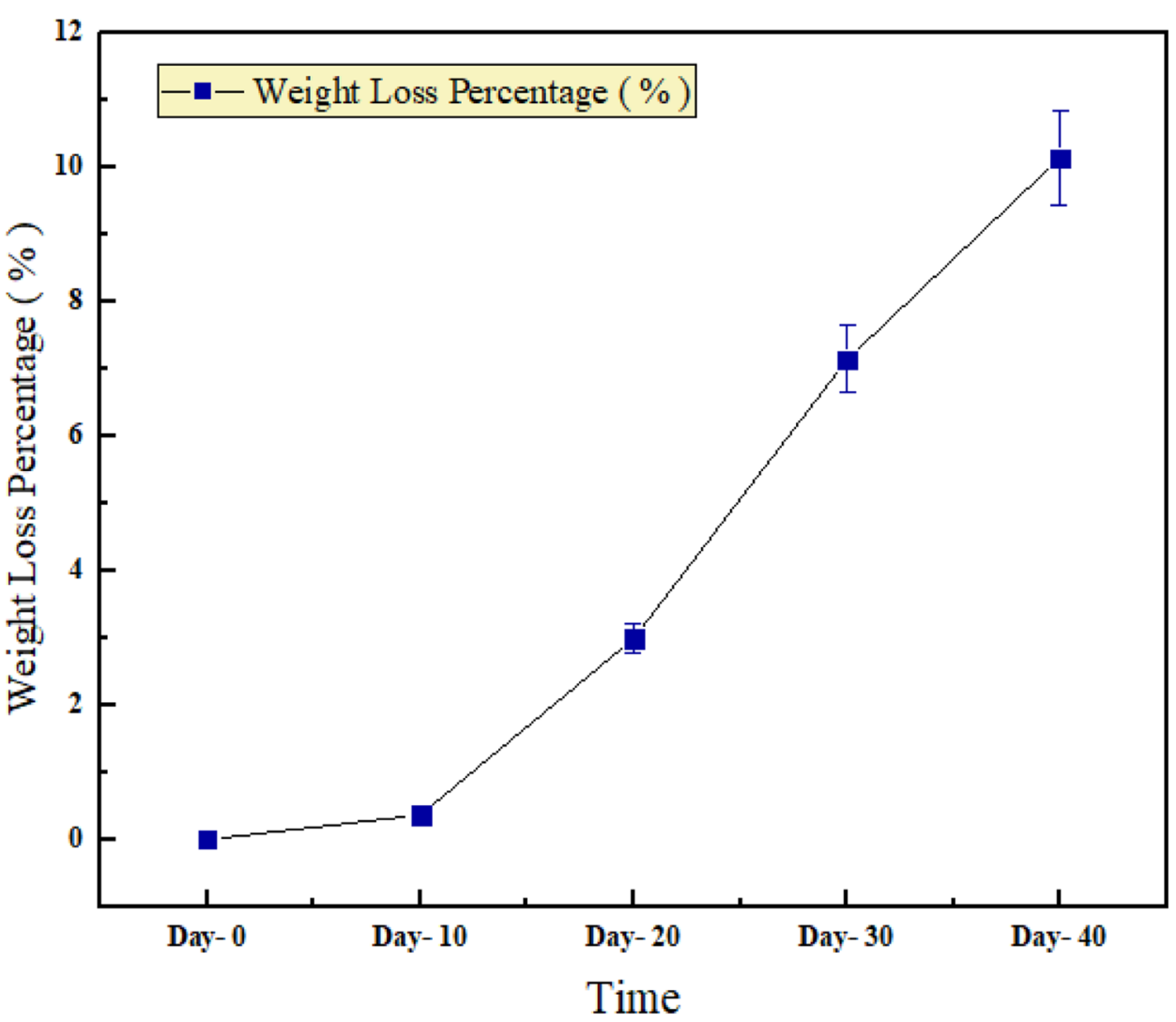


Fig. 7 Change in $\mathrm{pH}$ during bio-degradation of LDPE due to microbial activity

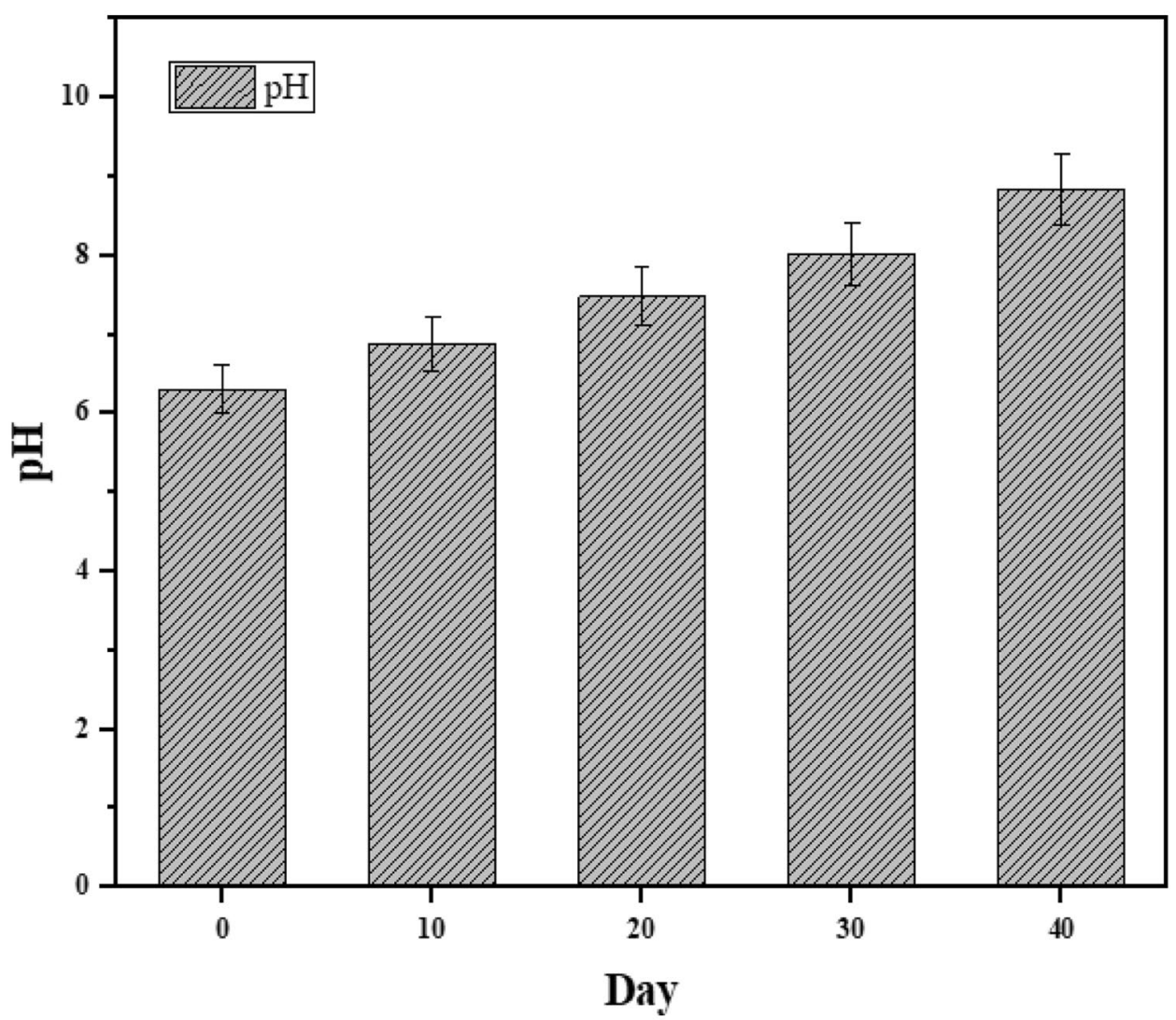

proclaimed. Usually, the microbes excrete different types of extracellular and intracellular enzymes, during the degradation of polymer films [16]. As a consequence of de-polymerization, the polymer composites are broken into monomers by the effect of exo-enzymes, which are microscopic enough to impregnate through the cell wall to be assimilated as sole carbon and the sources of energy [36]. The change in $\mathrm{pH}$ is basically due to the formation of metabolized enzyme secreted by the microbial strain after consumption of the sole carbon atoms present in the polymer films immersed in the media. Bacillus species being a neutrophile bacteria, effectively produce extracellular alkaline protease from sugar utilization of the media. As a result, of the accumulation of the metabolized enzyme, which is assuredly basic in nature, the $\mathrm{pH}$ of the media gradually increased. Furthermore, using the tryptone present in the media the bacterial strain leads to release ammonia which increases the $\mathrm{pH}$. Therefore it can be said that this type of degradation process using the bacteria tends to increase the soil fertility prominently.

\section{Change in contact angle}

The contact angle of the polymer film was measured to be 98.7 before the microbial treatment and it became 69.5 after the treatment of the film with microbial strain as shown in Table 5. Generally, the contact angle and hydrophilic
Table 5 Bio-chemical characterizations of the isolate.

\begin{tabular}{ll}
\hline Sample & Contact angle \\
\hline LDPE at initial state & $98.7^{\circ}$ \\
LDPE after 40 days of incubation with microbial & $69.5^{\circ}$ \\
strain & \\
\hline
\end{tabular}

character of polymer materials are inversely proportional to each other. From the FTIR result, it has been shown that after microbial treatment, a broad peak was observed prominently at $3375 \mathrm{~cm}^{-1}$, which was for acidic $\mathrm{O}-\mathrm{H}$ functional group, supporting the de-polymerization process of LDPE in the presence of Bacillus tropicus and the enhancement of hydrophilicity through the attachment of hydroxyl group. This enhancement of hydrophilic nature was well observed through the fall in contact angle. In SEM micrographs it was observed that after the microbial treatment, some folding, cracks, fragileness, erosions, and roughening of surface are significantly noticed on the LDPE film. As a result, the roughness of the film is increased, and subsequently, fall in contact angle is evidenced on the surface of the film. Similarly from AFM micrographs, the voids, cracks, grooves, and surface erosion of the LDPE film after the microbial treatment process were well observed. Such surface morphological changes tend to the high occupancy of water molecule 
into the grooves and voids which had been developed through the enzymatic degradation process. The wettability tends to enhance the hydrophilic characteristics and thus a noticeable fall in contact angle was observed which assured the enhancement of the hydrophilic nature of the LDPE film and evidenced the microbial degradation process. The occurrence of the surface disruption as identified in the SEM and AFM images indicated the increase in surface roughness after the incubation of the film in the microbial media. The enhancement in surface roughness is due to the breaking of the bonds of the highly crystalline structure of LDPE, creating pores and voids, which decrease the contact angle [37].

The decrease in contact angle resulted in an increase in the wettability along with the increase in corresponding hydrophilicity of the polymeric material. Such a result proclaimed that with increasing the immersion period in the liquid media, the polymer surface became comparatively more hydrophilic. Awasthi [16] and many reported works focused on the decrease in the contact angle of the polymer films of 20 microns and above. Nevertheless, till now increase in hydrophilic character in 10-micron polymer film, measured through the decrease in contact angle had not been reported earlier. The present study revealed the enhancement of the hydrophilic character of 10-micron polymer film after incubation with the microbial strain.

\section{Fourier-transform infrared spectroscopy (FTIR)}

The change in chemical structures of different LDPE films due to biodegradation was predicted by the FTIR spectroscopy analyzing the difference in non-identical FTIR spectra. By FTIR analysis, the change in chemical moieties, formation, or disappearance of any functional group, the existence of any antioxidant or filler, were also observed. In the present study (Fig. 8), the characteristic peak at $2915 \mathrm{~cm}^{-1}, 2928 \mathrm{~cm}^{-1}$, and $2848 \mathrm{~cm}^{-1}$ indicate the asymmetric and symmetric C-H stretching vibration respectively [38]. The band at $1470 \mathrm{~cm}^{-1}$ [39] became remarkably weaker after microbial treatment providing the evidence of the presence of the $\mathrm{C}=\mathrm{H}$ bond. The absorption bands at $718 \mathrm{~cm}^{-1}$ in both of the LDPE strip before and after incubation indicates the existence of $=\mathrm{C}-\mathrm{H}$ bending bond (mono). The current study revealed an immensely weak peak at $1370 \mathrm{~cm}^{-1}$ indicating the existence of the $\mathrm{C}-\mathrm{H}$ bending of $\mathrm{CH}_{2}$ [40]. After microbial treatment, a new band appeared

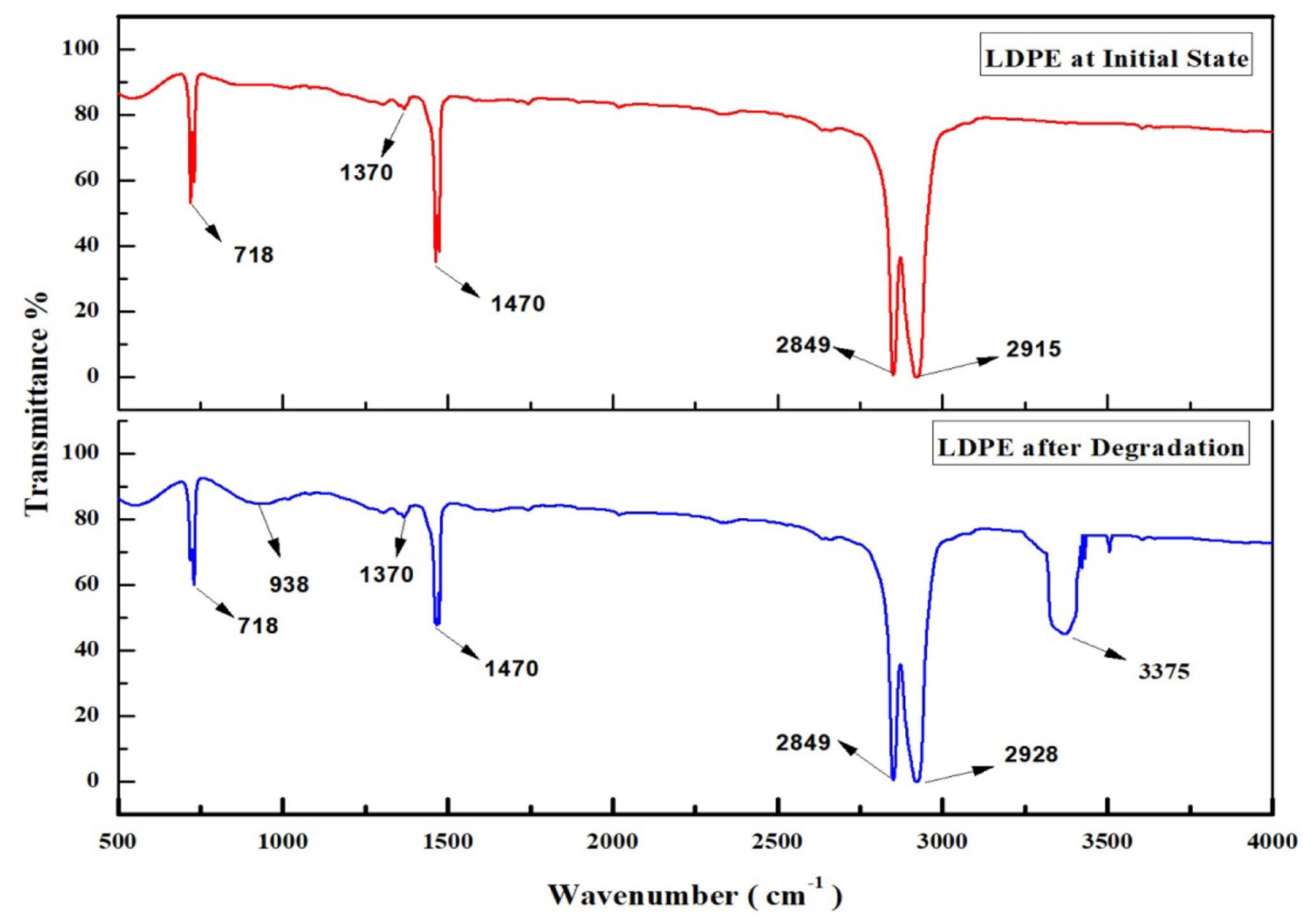

Fig. 8 FTIR spectra of (a) LDPE at the initial state, before microbial treatment; and (b) LDPE after treatment with microbial strain 
at $918 \mathrm{~cm}^{-1}$ which directed the presence of the $\mathrm{O}-\mathrm{H}$ bond promoting the bio-degradation of LDPE in the presence of the bacterial isolate [34]. Besides this, after microbial treatment, a broad peak was observed prominently at $3375 \mathrm{~cm}^{-1}$, which was for acidic O-H functional group, supporting the de-polymerization process of the LDPE matrix in the presence of the microbial strain [16]. The de-polymerization process of LDPE in the presence of Bacillus tropicus proved through the enhancement of hydrophilicity through the attachment of hydroxyl group. This enhancement of hydrophilic nature was well observed through the fall in contact angle. The strong noticeable peaks of LDPE at $1470 \mathrm{~cm}^{-1}$ and $718 \mathrm{~cm}^{-1}$ showed a major fall after microbial treatment. The de-polymerization action through the conformational diversity in the chemical structure as well as the surface of the LDPE films was well supported by the spectrophotometric analysis interpreting different absorption peaks and transmittance $\%$.

\section{Scanning electron microscopy (SEM) analysis}

Scanning electron microscopic analysis was done to figure out the variation in the surface of the LDPE films by evaluating the micrographs on which some grooves, cavities, or bioerosion have taken place after its microbial treatment. SEM analysis of LDPE films was used to investigate the diversity cropped up on the superficial morphology. Figure 9 demonstrates the surface morphology of the LDPE films through the SEM micrographs before microbial treatment (Fig. 9a). On the other hand, Fig. 9b shows some surface erosion and bacterial adhesion in a scattered manner indicating whitish coloration of the polymeric film after incubation. This probably may have occurred due to the enzymatic depolymerization process after treating the LDPE film with the microbial strain. After the microbial treatment, some folding, erosions, and some scattered bacterial colonization are significantly viewed on the surface of the LDPE film (Fig. 9b). As a result, the roughness of the film is increased and subsequently, loss in mass and fall in contact angle is evidenced on the surface of the film. Previous investigations have also reported the spectacular changes of bio-degraded polymer films using the SEM topology as a promising analytical system [14, 34, 41].

\section{Atomic force microscopy (AFM) analysis}

AFM micrographs validated the noticeable transformation in the surface of the LDPE film after microbial treatment in comparison with the film before getting treated with the microbial strain. Figs. 10.1a, 10.1b shows the 3D and 2D micrographs of LDPE film before microbial treatment, respectively. In the 2D micrograph of initial LDPE (Fig. 10.1b), there was no black spot or uneven surface observed and in the 3D micrograph (Fig. 10.1a), there was no distinct groove or fracture on the active surface site. While after treating the LDPE film with Bacillus tropicus, so many spectacular changes were observed (Fig. 10.2). In the 3D micrograph (Fig. 10.1b) of LDPE film after microbial treatment, several noticeable fractures, grooves, cavities, erupted surfaces were detected. The same result was observed and indicated by the black spots on the 2D micrograph (Fig. 10.2b) of the LDPE films after the incubation of it with the microbial strain. The grooves, cavities, fractures, and the erupted surface were formed by the bio-degradation process [14, 42]. Such surface morphological changes tend to the high occupancy of water molecule into the grooves and voids which had been developed through the enzymatic degradation process. The wettability tends to enhance the hydrophilic characteristics and thus a noticeable fall in contact angle was observed which assured the enhancement of the hydrophilic nature of the LDPE film and evidenced the microbial degradation process. The treated microbial strain had eaten up the individual carbon atoms present in the LDPE film through the enzymatic digestion technique.
Fig. 9 (9a) SEM micrograph of LDPE film before microbial treatment, (9b) SEM micrograph of LDPE film after incubation with microbial strain
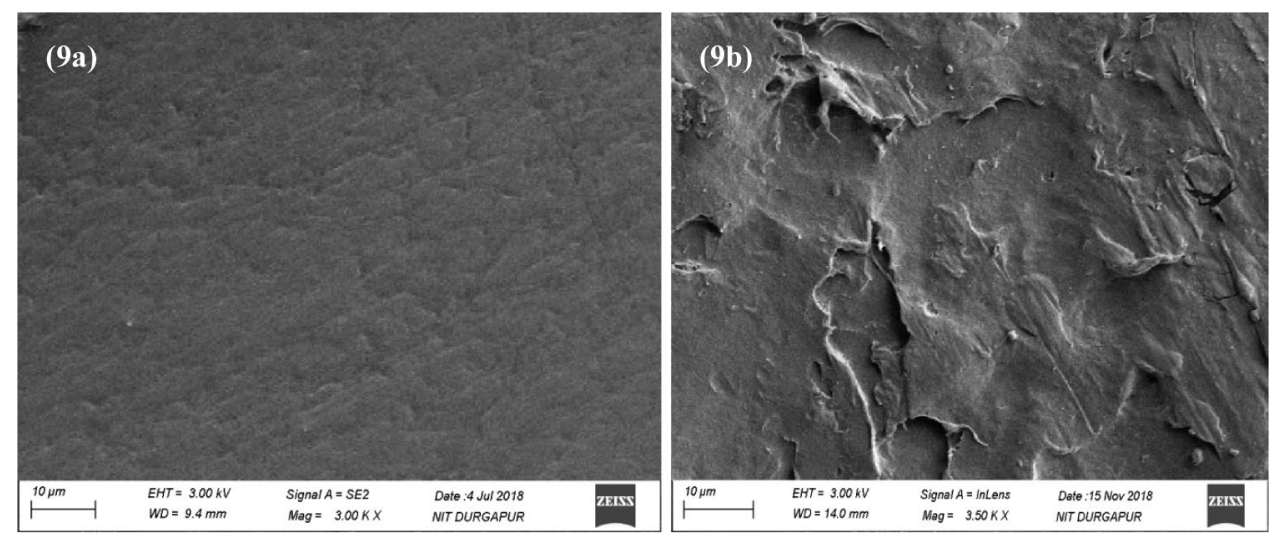
Fig. 10 AFM micrograph of LDPE film before microbial treatment, 10.1.(a) 3D image,

10.1.(b) $2 \mathrm{D}$ image and after microbial treatment, 10.2.(a) 3D image, 10.2.(b) 2D image
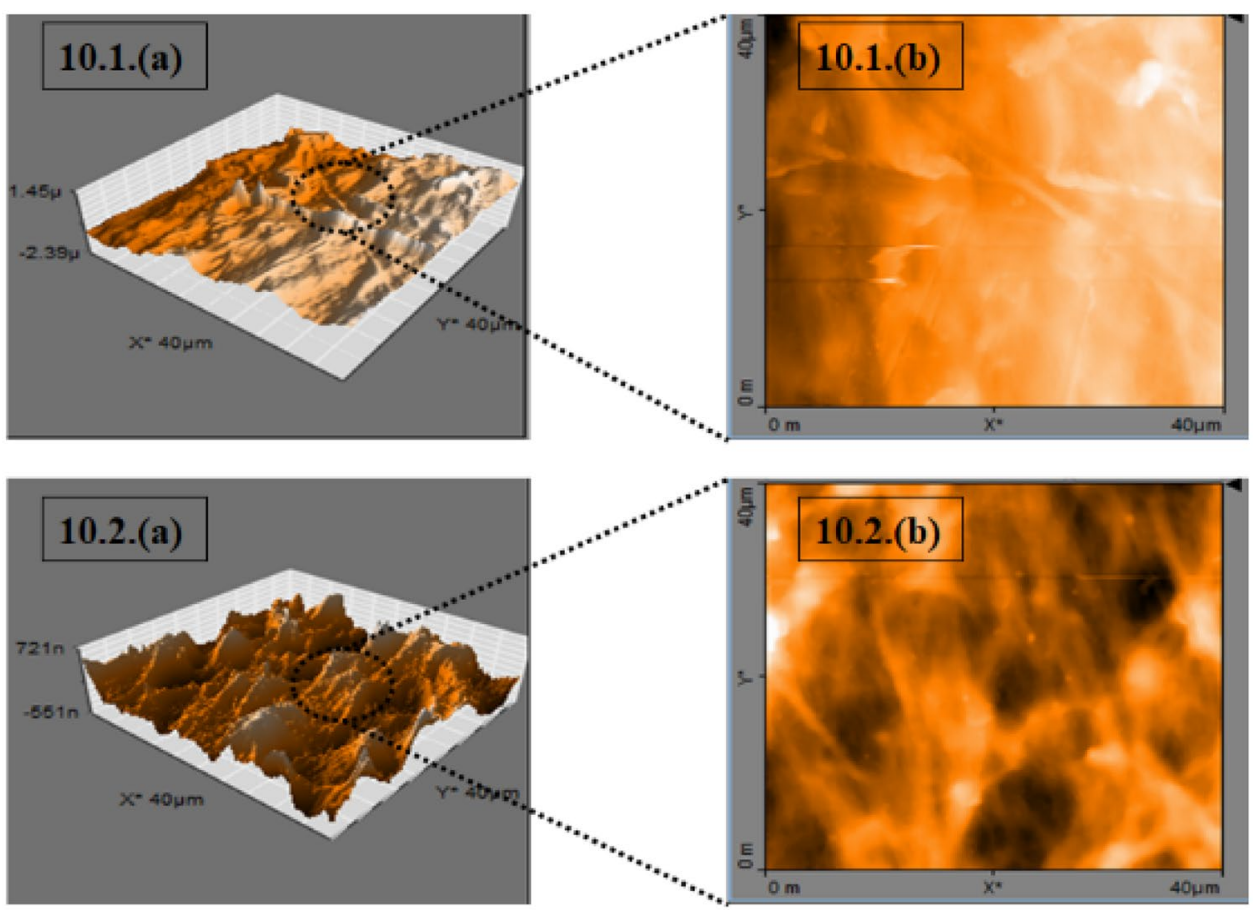

\section{Change in mechanical properties}

Different changes in the mechanical properties of the LDPE films were predominantly observed after treating it with the microbial strain during the degradation process. In the present study, various mechanical properties of the LDPE films, such as tensile strength, elongation at break, Young's Modulus, tear strength, hardness and stiffness were measured at its initial state and 10,20,30, 40 days of time interval respectively and shown in Fig. 11. The tensile strength,
Fig. 11 Change in different mechanical properties during the incubation period of the LDPE with different time intervals

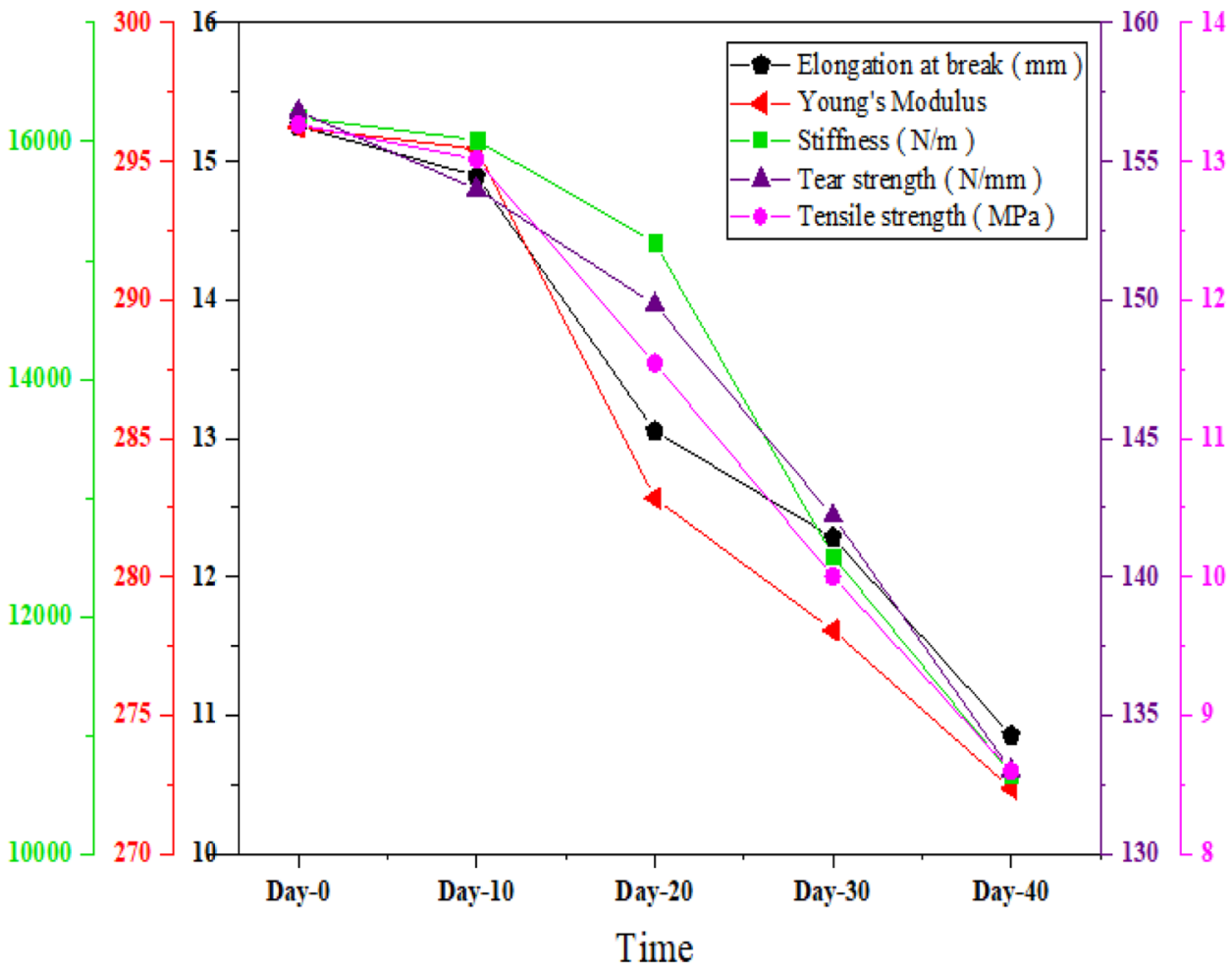


elongation at break, tear strength and Young's Modulus values of the LDPE films at its initial state were $13.26 \mathrm{MPa}$, $15.25 \mathrm{~mm}, 78.85 \mathrm{~N}$ and 296.22 respectively; whereas after 40 days of incubation, the corresponding values reduced to $8.59 \mathrm{MPa}, 10.85 \mathrm{~mm}, 69.18 \mathrm{~N}$ and 272.36 respectively. The decrease in the tensile strength, elongation at break, tear strength, and Young's Modulus values confirmed the reduction of homogeneity of the LDPE film due to microbial degradation. Due to the increase in void and cavities, loss of homogeneity on the surface of LDPE film was observed and this fact influenced to weaken the internal bonding between the ethylene functional groups of the long-chain LDPE matrix. Hardness and stiffness of the LDPE film also changed from 41 Shor D and 16,203.045 N/ $\mathrm{m}$ to 37.6 Shor D and 10,672.22 N/m respectively after 40 days of incubation in microbial incubation. Such a change in hardness and stiffness also assured the loss in mechanical properties, which ensured the bio-degradation of the LDPE film.

\section{Change in optical properties}

Figure 12 describes the haze and transparency of the LDPE film at different intervals of time during the incubation period. Initially, the transparency of the film was $98.7 \%$, which dropped to $93.7 \%$, whereas the haze percentage changed from 15.2 to $18.6 \%$ after 40 days of incubation. The continuous decline in transparency (\%) and an increase in haze values led to the formation of the opaque nature of the film under a suitable degrading environment [43]. Thus it can be concluded that Bacillus tropicus is promisingly capable of degrading the LDPE film by frictional abrasion of the superficial surface.

\section{Conclusion}

It can be concluded from the above experimental investigation that Bacillus tropicus, isolated from dumping site soil is a novel bacterium species that is undoubtedly effective to degrade LDPE films. The weight loss percentage after 40 days of incubation was found to be $10.15 \%$ due to the creation of voids and pores by fragmentation of the longchain polymer.Reduction in values of the mechanical properties also indicates the process of degradation of the films. The loss in mechanical properties can be justified by the decrease in tensile strength, tear strength, and elongation values from $13.26 \mathrm{MPa}, 78.85 \mathrm{~N}$ and $15.25 \mathrm{~mm}$ to $8.59 \mathrm{MPa}$, $69.18 \mathrm{~N}$ and $10.85 \mathrm{~mm}$ respectively. The stiffness and hardness values of a film are an indicator of the capability of a film to resist deformation against an external load. The susceptibility of the films towards declination of the values of hardness and stiffness from 41 Shor D and 16,203.05 N/m to 37.6 Shor D and 10,672.22 N/m respectively after 40 days is a clear indication of the creation of internal voids leading to the reduction of the intermolecular structural compactness. The change in the molecular structural arrangement can also
Fig. 12 Change in the optical properties (Haze \& Transmittance percentage) of LDPE film during the incubation period with different time intervals

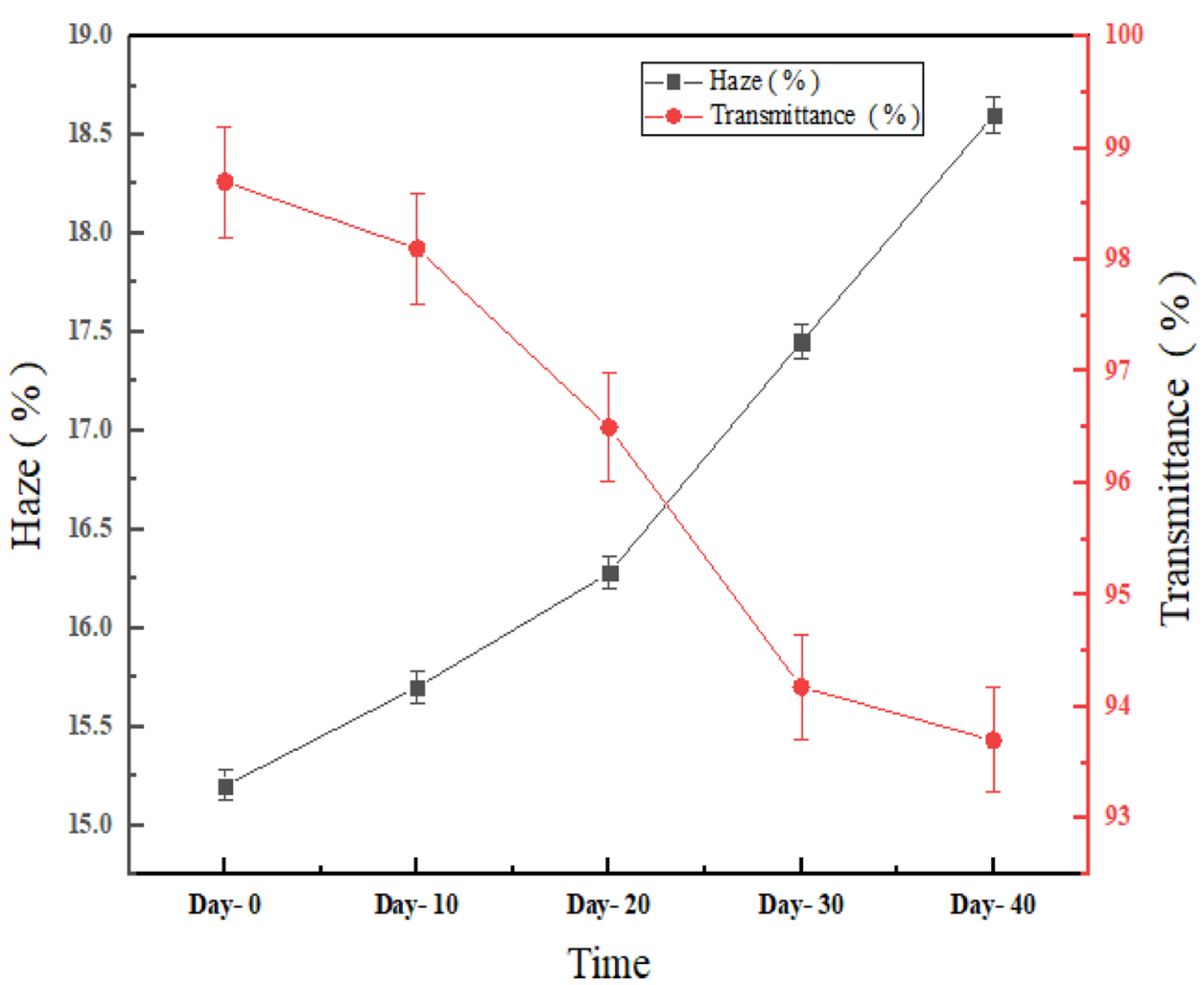


be justified by the decrease in transparency of the films from 98.7 to $93.7 \%$, and the increase in the haze percentage from 15.2 to $18.6 \%$. The work also elaborates on the degradation study of never explored 10-micron thick LDPE film using Bacillus tropicus as a relevant bacterium sp. The FTIR analysis result showed few intra and inter-molecular changes in the polymeric structure revealing the change in microstructural bond arrangement due to biodegradation. The contact angle measurement imposed the fact of increasing the hydrophilicity observed by the decrease in the contact angle of the film. The increasing trend in haze and decreasing trend in transparency also explains the microbial degradation on the surface of the LDPE film affecting the light scattering phenomena. SEM and AFM result broadly elaborated on the change in the surface morphology of the LDPE film due to the quantification of the novel sp. Bacillus tropicus. In the world, there are many scientific findings on microbial degradation study on the polymeric material, but using Bacillus tropicus as a suitable polymer degradable bacterium strain is unique. Thus this work suggests the development of a new bacterial strain usually present in a normal dumping site for the degradation of very low thickness film to reduce the present threat of over-accumulation of polymeric materials creating huge environmental pollution.

Acknowledgment Authors would like to convey their gratitude to the Department of Science \& Technology, Govt. of West Bengal, India, for the monetary support through the research project ST/P/S\&T/ IG-9/2016. The authors are obliged to the Chemical Engineering Department, National Institute of Technology Durgapur, India, for the instrumentation facilities.

\section{Compliance with Ethical Standards}

Conflict of interest Authors declare that there are no conflicts of interest to disclose.

\section{References}

1. Shimao M (2001) Biodegradation of plastics. Curr Opin. Biotech 12:242-247

2. Sen SK, Rout S (2015) Microbial degradation of low density poly ethylene (LDPE): A review. J Environ Chem Eng 3:462-473

3. Ohtake Y, Kobayashi T, Asabe H, Murakami N (1998) Studies on biodegradation of LDPE - observation of LDPE films scattered in agricultural fields or in garden soil. Polym Degrad Stabil 60:79-84

4. Ritch E, Brennan C, MacLeod C (2009) Plastic bag politics: modifying consumer behaviour for sustainable development. Int J Consum Stud 33(2):168-174

5. Napper IE, Thompson RC (2019) Environmental Deterioration of Biodegradable, Oxo-biodegradable, Compostable, and Conventional Plastic Carrier Bags in the Sea, Soil, and Open-Air Over a 3-Year Period. Environ Sci Technol 53:4775-4783

6. Besseling E, Wegner A, Foekema EM, van den Heuvel-Greve MJ, Koelmans AA (2012) Effects of Microplastic on Fitness and
PCB Bioaccumulation by the Lugworm Arenicola marina (L.). Environ Sci Technol 47(1): 593-600.

7. Accinelli C, Abbas HK, Bruno V, Nissen L, Vicari A, Bellaloui N, Little NS, Thomas Shier W (2020) Persistence in soil of microplastic films from ultra-thin compostable plastic bags and implications on soil Aspergillus flavus population. Waste Manage 113:312-318

8. Rivers N, Shenstone-Harris S, Young N (2017) Using nudges to reduce waste? The case of Toronto's plastic bag levy. J Environ Manage 188:153-162

9. Scott G (2000) Green Polymers Polym Degrad Stabil 68:1-7

10. Parcella M, Pazzagli F, Galeski A (2002) Reactive compatibilization and properties of recycled poly (ethylene terephthalate)/ polyethylene blends. Polym Bullet 48:67-74

11. Gopferich A (1996) Mechanisms of polymer degradation and erosion. Biomaterials 17:103-114

12. La Mantia FP, Morreale M, Botta L, Mistretta MC, Ceraulo M, Scaffaro R (2017) Degradation of polymer blends: A brief review. Polym Degrad Stabil 145:79-92

13. Restrepo-Flórez JM, Bassi A, Thompson MR (2014) Microbial degradation and deterioration of polyethylene - A review. Int Biodeter Biodegr 88:83-90

14. Tribedi P, Sil AK (2013) Low-density polyethylene degradation by Pseudomonas sp. By AKS2 biofilm. Environ Sci Pollut Res 20:4146-4153

15. Gajendiran A, Krishnamoorthy S, Abraham J (2016) Microbial degradation of low-density polyethylene (LDPE) by Aspergillus clavatus strain JASK1 isolated from landfill soil. 3 Biotech 6:52.

16. Awasthi S, Srivastava N, Singh T, Tiwary D, Mishra PK (2017) Biodegradation of thermally treated low density polyethylene by fungus Rhizopus oryzae NS 5. 3 Biotech 7:73. Watanabe T, Ohtake Y, Asabe H, Murakami N, Furukawa M (2009) Biodegradability and degrading microbes of low-density polyethylene. J Appl Polym Sci 111:551-559

17. Volke-Sepulveda T, Saucedo-Castañeda G, Gutierrez-Rojas M, Manzur A, FavelaTorres E (2002) Thermally treated low density polyethylene biodegradation by Penicillium pinophilum and Aspergillus niger. J Appl Polym Sci 83:305-314

18. Roy PK, Titus S, Surekha P, Tulsi E, Deshmukh C, Rajagopal C (2008) Degradation of abiotically aged LDPE films containing pro-oxidant by bacterial consortium. Polym Degrad Stab 93:1917-1922

19. Vimala P, Mathew L (2016) Biodegradation of Polyethylene using Bacillus subtilis: International Conference on Emerging Trends in Engineering, Science and Technology (ICETEST2015). Proc Technol 24:232-239.

20. Mukherjee S, Sahu P, Halder G (2017) Microbial remediation of fluoride-contaminated water via a novel bacterium Providencia vermicola (KX926492). J Environ Manage 204:413-423

21. Legal Limits on Single-Use Plastics and Microplastics: A Global Review of National Laws and Regulations (2018) United Nations Environment Programme, United Nations. https://www. unenvironment.org. Accessed 14 May 2020

22. Yuan J, Ma J, Sun Y, Zhou T, Zhou Y, Yu F (2020) Microbial degradation and other environmental aspects of microplastics/ plastics. Sci Tot Environ 715:136968

23. Lonnstedt OM, Eklov P (2016) Environmentally relevant concentrations of microplastic particles influence larval fish ecology. Science 352(6290):1213-1216

24. Rochman CW, Browen MA, Halperns BS, Hentschel IB, Hoh E (2013) Classify plastic waste as hazardous. Nature 494(7436):169-171

25. Wang J, Huang M, Wang Q, Sun Y, Zhao Y, Huang Y (2020) LDPE microplastics significantly alter the temporal turnover of soil microbial communities. Sci Tot Environ 726:138682 
26. Rujnic-Sokele M, Pilipovic A (2017) Challenges and opportunities of biodegradable plastics: a mini review. Waste Manag Res 35:132-140

27. Zakaria ZA, Zakaria Z, Surif S, Ahmad WA (2007) Hexavalent chromium reduction by Acinetobacter haemolyticus isolated from heavy-metal contaminated wastewater. J Hazard Mater 146:30-38

28. Mondal M, Ghosh A, Sharma AS, Tiwari ON, Gayen K, Mandal MK, Halder GN (2016) Mixotrophic cultivation of Chlorella sp. BTA 9031 and Chlamydomonas sp. BTA 9032 isolated from coal field using various carbon sources for biodiesel production. Energy Conver Manage 124:297-304

29. Kyaw BM, Champakalakshmi R, Sakharkar MK, Lim CS, Sakharkar KR (2012) Biodegradation of low density polyethene (LDPE) by Pseudomonas species. Indian J Microbiol 52(3):411-419

30. Egli T (2009) Growth Kinetics, Bacterial. Encyclopedia of Microbiology. (Moselio Schaechter, Editor), pp. 180-193. Oxford: Elsevier.

31. Gilan I, Hadar Y, Sivan A (2004) A Colonization, biofilm formation and biodegradation of polyethylene by a strain of Rhodococcus ruber. Appl Microbiol Biotechnol 65:97-104

32. Balasubramanian V, Nataraja K, Rajeshkannan V, Perumal $P$ (2014) Enhancement of in vitro high-density polyethylene (HDPE) degradation by physical, chemical, and biological treatments. Environ Sci Pollut Res 21:12549-12562

33. Das PM, Kumar S (2015) An approach to low-density polyethylene biodegradation by Bacillus amyloliquefaciens. 3 Biotech 5:81-86.

34. Hadad D, Geresh S, Sivan A (2005) Biodegradation of polyethylene by the thermophilic bacterium Brevibacillus borstelensis. J Appl Microbiol 98(5):1093-1100

35. Dey U, Mondal NK, Das K, Dutta S (2012) An approach to polymer degradation through microbes. IOSR J Pharm 2:385-388

36. Chun KS, Husseinsyah S, Syazwani NF (2015) Properties of kapok husk-filled linear low-density polyethylene ecocomposites: Effect of polyethylene-grafted acrylic acid. J Thermoplast Compos $1-15$.

37. Wang J, Wu Y, Cao Y, Li G, Liao Y (2020) Influence of surface roughness on contact angle hysteresis and spreading work. Colloid Polym Sci 1-7.
38. Jamil SUu, Zada S, Khan I, Sajjad W, Rafiq M, Shah AA, Hasan F (2017) Biodegradation of polyethylene by bacterial strains isolated from Kashmir Cave, Buner. Pakistan J Cave Karst Stud 79(1):73-80

39. Datta D, Halder G (2018) Enhancing degradability of plastic waste by dispersing starch into low density polyethylene matrix. Process Saf Environ 114:143-152

40. Auta HS, Emenike CU, Fauziah SH (2017) Screening of Bacillus strains isolated from mangrove ecosystems in Peninsular Malaysia for microplastic degradation. Environ Pollut 231(2):1552-1559

41. Tribedi P, Sarkar S, Mukherjee K, Sil AK (2012) Isolation of a novel Pseudomonas sp from soil that can efficiently degrade polyethylene succinate. Environ Sci Pollut Res 19:2115-2124

42. Manzur A, Limon-Gonzalez M, Favela-Torres E (2004) Biodegradation of physicochemically treated LDPE by a consortium of filamentous fungi. J Appl Polym Sci 92(1):265-271

43. Datta D, Samanta S, Halder G (2019) Surface functionalization of extracted nanosilica from rice husk for augmenting mechanical and optical properties of synthesized LDPE-Starch biodegradable film. Polym Test 77:105878

44. Sivan A, Szanto M, Pavlov V (2006) Biofilm development of the polyethylene-degrading bacterium Rhodococcus ruber. Appl Microbiol Biotechnol 72(2):346-352

45. Abraham J, Ghosh E, Mukherjee P, Gajendiran A (2016) Microbial degradation of low-density polyethylene. Environ Prog Sustain Energy 36(1):147-154

46. Nourollahi A, Sedighi-Khavidak S, Mokhtari M, Eslami G, Shiranian M (2018) Isolation and identification of low-density polyethylene (LDPE) biodegrading bacteria from waste landfill in Yazd. Int J Environ Stud 76(2):236-250

Publisher's Note Springer Nature remains neutral with regard to jurisdictional claims in published maps and institutional affiliations. 